\title{
Procesos de acompañamiento de estudiantes con discapacidad en su ingreso a la Universidad: transiciones entre nivel secundario y superior.
}

\author{
Accompaniment processes for students with disabilities when \\ they enter the University: transitions between High School and \\ Higher Education.
}

\author{
Mónica Inés Delgado \\ https://orcid.org/0000-0002-9883-6177 \\ midelgado1680@gmail.com \\ Universidad Nacional de Río Negro | \\ Instituto de Formación Docente Continua | \\ Bariloche, Argentina
}

\section{RESUMEN}

Este escrito describe la experiencia educativa en prácticas de acompañamiento a las trayectorias académicas de estudiantes con discapacidad en el ingreso al nivel superior. Suma sentidos valiosos que permiten ubicar estrategias y apoyos desplegados desde un equipo pedagógico, bajo los lineamientos de un Programa integral de Accesibilidad que la Universidad desarrolla desde hace varios años.

Esta propuesta institucional, se asienta en un marco político pedagógico pero también epistemológico, desde donde se desarrollan procesos de acompañamiento académico. Por un lado, desde perspectivas que garantizan el derecho a la educación en personas con discapacidad que eligen transitar este nivel educativo. Y por otro, en torno a posiciones críticas respecto a concepciones de discapacidad, trayectorias, y de acompañamiento.

Desde un equipo de trabajo interdisciplinar se vienen construyendo recursos institucionales que transversalizan la perspectiva de accesibilidad académica y que se constituyen en configuraciones de apoyo, propiciando el trabajo en red y colaborativo. A su vez la tarea de profesionales que desde el campo educativo sostienen y propician dichas construcciones en pos del acompañamiento en trayectorias e itinerarios de estudiantes, que provienen principalmente de la escuela secundaria rionegrina y comienzan su tránsito por la Educación Superior.

PALABRAS CLAVE acompañamiento, trayectorias académicas, discapacidad, derecho a la educación 


\section{KEY WORDS}

accompaniment, academic trajectories, disability,

right to education

\section{ABSTRACT}

This paper describes the educational experience in accompanying practices of the students with disabilities academic trajectories when entering into the Higher Education. It adds valuable senses that allow locating strategies and supports from a pedagogical team, under the guidelines of a comprehensive Accessibility Program that the university has been developing for several years.

This institutional proposal is based on a pedagogical but also epistemological political framework, from where academic support processes are developed. On the one hand, from perspectives that guarantee the right to education for people with disabilities who choose to go through this educational level.And on the other, around critical positions regarding conceptions of disability, trajectories, and support.

From an interdisciplinary work team, institutional resources have been developed to support the perspective of academic accessibility and promoting collaborative networking. At the same time, the task of professionals who, from the educational field, support and promote said constructions in pursuit of the accompaniment in the trajectories and itineraries of students, who mainly come from Rio Negro high school and begin their transit through Higher Education. 


\section{PRESENTACIÓN}

Los procesos históricos educativos en nuestro país relacionados con aquellas situaciones de desigualdad y segregación que producen desventajas en el ingreso de jóvenes a la Educación Superior (Tiramonti, 2004; Dussell, 2008; Perez, Gallardo, Schewe, 2019), muestran y demandan profundas intervenciones institucionales, en el apoyo a las trayectorias de estudiantes con discapacidad (Ecd en adelante) para este nivel.

En Perez, Gallardo, Schewe (2019), se puede leer que en los orígenes históricos de la educación argentina, estas desigualdades educativas, en la relación discapacidad y derecho a la educación, han sido atravesadas por discursos y prácticas en torno a las personas con discapacidad construidas en y desde la exclusión educativa y social. Para las autoras, el lugar de la modalidad de Educación Especial y de la Escuela Especial como instituciones de este tiempo, conjuntamente al del sistema educativo argentino, y el de las trayectorias de vida en Ecd, han estado: "cargadas de una sobredeterminación de la institucionalización" y de "perspectivas centradas en el déficit y en la rehabilitación, más que en la potencialidad y en el goce pleno de todos los derechos"(p. 24).

En este orden y en posibilidad que brindan los marcos normativos junto a regulaciones para la Educación Superior, pero también en los acuerdos construidos para los niveles educativos anteriores y en lo particular de la experiencia de la educación secundaria rionegrina y del acompañamiento a las trayectorias de Ecd en ese nivel. Aquí, interesa detenernos en algunas prácticas pedagógicas e institucionales al interior de la UNRN, que promueven la inclusión y garantizan el derecho a la educación de Ecd en el nivel (Perez, Roldan y Vain, 2021; Misischia, 2014 y 2020; Rositto, 2017). Es decir prácticas que dan continuidad pedagógica a procesos de acompañamiento vinculados al nivel anterior, en tanto configuraciones que se reconstruyen en este 
nuevo espacio constituido por el nivel superior, y consideran aquellos trayectos y experiencias pedagógicas anteriores.

Interesa en este trabajo, además de avanzar en la caracterización de acciones y estrategias que se promueven desde un equipo pedagógico en la universidad, junto a docentes y no docentes, pero principalmente en diálogo con el Esd, y en el marco del Programa integral de accesibilidad de la UNRN. También, ofrecer otros sentidos que permitan la comprensión de la experiencia de acompañamiento a las trayectorias en este nivel.

\section{DESARROLLO}

El pasaje y la transición de la escuela secundaria obligatoria en nuestro país (Nobile, 2016; Acosta, 2012; Dussell, 2010; Southwell, 2018), y para el caso de la provincia de Río Negro, nos lleva a atender al proyecto educativo que se desarrolla en la denominada ESRN - Escuela Secundaria rionegrina- (Foures, 2018; Araujo, 2021). Donde la mayor parte de Ecd que inician sus estudios en la UNRN y dan continuidad a sus trayectorias educativas, provienen de este proyecto para el nivel secundario en la provincia de Río Negro.

En la posibilidad de articulación y de acompañamiento en aquellos tránsitos de un nivel educativo obligatorio a otro no obligatorio, como es el caso de la Educación Superior. Desde hace algunos años la UNRN en su sede Andina, viene desarrollando desde un equipo pedagógico (APD)1, una tarea de reconocimiento de aquellas ESRN (Escuelas secundarias rionegrinas), en las que han transitado Ecd, en los denominados procesos de inclusión para ese nivel, y que luego pueden vehiculizar la continuidad de trayecto en el espacio universitario. Esta propuesta de trabajo articulado es promovida en el contexto del "Programa Integral de Accesibilidad" (2018) a través de diversas construcciones y apoyos, que tienen lugar en la universidad de Río Negro en sus distintas sedes. (Delgado, Zambianchi y otros, 2021).

Sobre estas condiciones pedagógicas que promueven procesos de inclusión y accesibilidad en el nivel, interesa avanzar. En la posibilidad de revisar aquellas acciones y estrategias que tienen lugar en los procesos de acompañamiento de Ecd en el nivel, en torno al trabajo desde el Programa Integral de Accesibilidad de la UNRN y de un equipo pedagógico que avanza sobre los principios de este programa institucional transversalizando la perspectiva de discapacidad y acompañamiento a las trayectorias académicas.

En este sentido, comprendemos el valor y la fuerza del acompañamiento a las trayectorias en Ecd, desde el primer contacto de estudiantes con la universidad, en ocasiones previo al ingreso y a su condición de alumnxs regulares. La importancia de encontrarnos como equipo pedagógico con documentos institucionales de la ESRN, de los 
equipos directivos, docentes vinculados al recorrido del último año de esa escuela y algunas voces docentes, que dan cuenta del acompañamiento allí desarrollado.

En este sentido, comprendemos el valor y la fuerza del acompañamiento a las trayectorias en Ecd, desde el primer contacto de estudiantes con la universidad, en ocasiones previo al ingreso y a su condición de alumnxs regulares.

Esta mirada se suma al conocimiento de cada estudiante, aunque de modo principal este sentido se construye bajo el aporte de actores fundamentales en este proceso y desarrollo de las trayectorias académicas en este nivel, como lo son Ixs mismxs estudiantes. Por ello, allí está puesto el foco de nuestra propuesta y desde esas voces se construye proyecto pedagógico y académico, que deja huellas significativas en el espacio institucional y en las prácticas educativas.

Resulta importante dar cuenta de la concepción sostenida y compartida como equipo, acerca de las trayectorias educativas, entendidas tal como traza Bracchi (2016) y nos permite situar para pensar el acompañamiento de Ecd en la Educación Superior. En tanto trayectorias que:

“...permiten considerar y reconocer todos aquellos ámbitos formativos por los cuales se van conformando las biografías y los recorridos de los estudiantes (...) Estas trayectorias educativas hacen referencia al conjunto de todos aquellos condicionantes (experiencias, saberes, etc) que inciden en el recorrido de los sujetos por las instituciones" ( $p .7$ )

Estos recorridos, trayectorias e historias de vida, se despliegan en el encuentro con apoyos y recursos que andamian la actividad de aprendizaje, pero también la de enseñanza como procesos complejos. Cuando un equipo pedagógico, como el de APD "asistentes pedagógicos en discapacidad", figura creada en el marco del Programa de Accesibilidad de la UNRN, hace lugar a aquellas tramas en donde confluye la vivencia estudiantil, la práctica docente y la experiencia pedagógica de acompañamiento que tiene lugar y se hace camino.

Estos recorridos, trayectorias e historias de vida, se despliegan en el encuentro con apoyos y recursos que andamian la actividad de aprendizaje, pero también la de enseñanza como procesos complejos.

Escuchar en las voces de estudiantes pero también de estas figuras pedagógicas de APD, aquellos sentidos, que se nutren desde perspectivas críticas acerca de la discapacidad (Brogna, 2009; Misischia, 2020) de la formación docente y de la educación en el nivel, nos permite de- 
construir y volver a evocar nuevas construcciones y "configuraciones de apoyo" (Rusler y otros, 2019), elaboradas desde miradas didácticas y pedagógicas también críticas.

Estas construcciones pedagógicas que tienen lugar en diálogo con equipos docentes en el acompañamiento de Ecd, nos invitan a una permanente reflexión acerca también de la concepción de discapacidad. Para ello nos valemos, en Brogna (2019), de una apreciación que interpela sentidos a veces comunes, presentes en las voces docentes en el nivel, y que pueden obturar otras prácticas pedagógicas en procesos de inclusión que puedan tener lugar en la Educación Superior. La autora propone:

“Escapar de la conceptualización de la discapacidad como déficit individual, entender la vivencia y la experiencia subjetiva desde una mirada que la resignifique como el ejercicio de cuestionamientos a las estructuras, de resistencias culturales y políticas en un nivel micro de la realidad no aislable de los otros niveles sociales, demandará volver visible aquellas estrategias, dispositivos, juegos de verdad y tecnologías que el peso del diagnóstico legítima y normaliza" ( $p .43$ )

De alguna manera, las configuraciones de apoyo resignificadas y reconstruidas en el ingreso a la Educación Superior, vienen a demandar miradas atentas y críticas respecto a la situación de discapacidad. Aunque también apuntan al conocimiento de los programas institucionales como el de accesiblidad, por parte de cada miembro de la institución, y que en la actualidad ofrece otras perspectivas respecto al acompañamiento de las trayectorias académicas en este nivel.

Aquellas configuraciones en tanto andamiajes institucionales, tienen lugar de modos concretos en conversación con las supervisiones educativas en nuestro territorio, aquellas denominadas Supervisiones de Educación Secundaria y de Educación Especial. En ese diálogo, en la búsqueda de información e intercambio respecto a las trayectorias de Ecd por ese nivel y en la transición hacia la Educación Superior, como lugares de trabajo sobre ese tránsito que también hoy propicia la ESRN, como principio para el acompañamiento a las trayectorias en el pasaje a la Educación Superior.

Finalmente mencionar en torno a estas configuraciones que aquí venimos abordando y resignificando desde aquellos apoyos construidos en niveles anteriores por donde han transitado Ecd. Que los mismos encuentran, también en normativas elaboradas en el territorio rionegrino como la Resolución 3438/11 que expone aquellos "Lineamientos para la Inclusión de los alumno/as con discapacidad en establecimientos educativos de nivel inicial, primario y medio", y el documento denominado "Configuraciones de apoyo para estudiantes con discapacidad en la escuela secundaria obligatoria". En ambas producciones coordenadas de valor para situar las prácticas de acompañamiento desde el equipo pedagógico de nuestra universidad y en 
el contexto del "Programa integral de Accesibilidad". Al igual, que la revisión de posiciones que permitan situar otras prácticas educativas que tengan lugar en el espacio de la Educación Superior.

De alguna manera, las configuraciones de apoyo resignificadas y reconstruidas en el ingreso a la Educación Superior, vienen a demandar miradas atentas y críticas respecto a la situación de discapacidad. 


\section{BIBLIOGRAFÍA}

Acosta, F. (2012). La escuela secundaria argentina en perspectiva histórica y comparada: modelos institucionales y desgranamiento durante el siglo XX. Cadernos de História da Educação, 11(1).

Araujo, F. V. (2021). Interdisciplinariedad en la ESRN. Un proyecto institucional cuestionador del modo fragmentado de interpretar el mundo (Bachelor's thesis, Universidad Nacional del Comahue. Facultad de Ciencias de la Educación).

Bracchi, C. (2016). Descifrando el oficio de ser estudiantes universitarios: entre la desigualdad, la fragmentación y las trayectorias educativas diversificadas. Trayectorias universitarias, 2(3), 3-14.

Brogna, P. (2009). Las representaciones de la discapacidad: la vigencia del pasado en las estructuras sociales presentes. En Brogna, P. (comp.) Visiones y revisiones de la discapacidad. pp. 157 - 187. México: Fondo de Cultura Económica.

Brogna, P. (2019). El campo académico de la discapacidad: pujas por el nodo de sentido. Acta Sociológica, (80), 25-48.

Delgado, M. I., Zambianchi, V., Sepúlveda, P., \& Sosa Dansey, R. (2021). Experiencia de Implementación del Programa de accesibilidad y discapacidad UNRN: configuraciones y apoyos en procesos de continuidad pedagógica en contexto ASPO y DISPO en Sede Andina.

Dussel, I. (2008). Desigualdad social y desigualdad educativa. Programa interdisciplinario de investigaciones en educación.

Fourés, C. I. (2018, May). La trama compleja de relación entre una nueva propuesta curricular y las prácticas docentes cotidianas: un estudio de caso sobre la Escuela Secundaria de Río Negro (ESRN). In [2018] Congreso Internacional de Educación y Aprendizaje.

Misischia, B. S. (2014). Derecho a la educación universitaria de personas con discapacidad. Revista latinoamericana de educación inclusiva, 8(1), 25-33.

Misischia, B. S. (2020). Políticas universitarias, perspectiva de discapacidad y accesibilidad en Argentina.

Nobile, M. (2016). La escuela secundaria obligatoria en Argentina: Desafíos pendientes para la integración de todos los jóvenes. Última década, 24(44), 109-131.

Pérez, A. V., Gallardo, H. H., \& Schewe, C. L. (2019). Acerca de los orígenes his- 
tóricos de las desigualdades educativas en la Argentina: discapacidad y derecho a la educación hoy.

Pérez, A. V., Roldán, E. O., \& Vain, P. D. (2021). Presentación del Dossier especial sobre discapacidad en educación superior. Revista Argentina de Educación Superior, (22), 18-21.

Rositto, S. A. (2017). Derecho a la Educación Superior de las Personas en Situación de Discapacidad en Argentina.

Southwell, M. (2013). Destinos y salidas: escuelas medias frente a la desigualdad. En: Southwell, M. y Romano, A. (Comps.): La escuela y lo justo. UNIPE, Buenos Aires. pp. 57 - 83.

Tiramonti, G. (2004). La fragmentación educativa y los cambios en los factores de estratificación. La trama de la desigualdad educativa. Mutaciones recientes en la escuela media, 15-45.

Tiramonti, G. (2016). Notas sobre la configuración de la desigualdad educativa en América Latina. Revista Internacional de Educación para la Justicia Social (RIEJS).

\section{DOCUMENTOS}

Consejo Interuniversitario Nacional (2021) Disponibilidad e implementación de estrategias de accesibilidad y ajustes razonables, en los sistemas de educación a distancia (SIED) implementados por las instituciones universitarias nacionales y provinciales. Enlace al texto del Consejo Interuniversitario Nacional

Consejo Interuniversitario Nacional (2020) Programa Integral de Accesibilidad para las Universidades Públicas. Ampliación, profundización y operativización. Acuerdo plenario n¹104/20. Red Interuniversitaria de Discapacidad de la Comisión de Extensión, Bienestar Universitario y Vinculación Territorial.

Diseño Curricular ESRN, Ministerio de Educación y Derechos Humanos Río Negro,Resolución 945/17, Anexo I.

Resolución №3438/11 Lineamientos para la Inclusión de los alumno/as con discapacidad en establecimientos educativos de nivel inicial, primario y medio. Diciembre 2011. Ministerio de Educación. Provincia de Río Negro, Argentina.

Documento, "Configuraciones de apoyo para estudiantes con discapacidad en la escuela secundaria obligatoria. En base a la Res. CPE 3438/11", Dirección de Inclusión Educativa, Educación Especial y Asistencia Técnica. Ministerio de Educación y Derechos Humanos, Gobierno de Río Negro. 
Programa Integral de Accesibilidad de la UNRN (2018).

\section{NOTAS:}

1. Establecido desde el "Programa Integral de Accesibilidad" la UNRN cuenta en cada una de sus sedes, con un grupo de profesionales que acompañan las trayectorias de estudiantes con discapacidad en el nivel (denominados -APD- asistentes pedaógicxs en discapacidad) y trabajan junto a los equipos docentes y no docentes en pos de la construcción y promoción de la accesibilidad académica en el contexto de dicho programa institucional. 